\title{
DENSIDADE DO FUNCIONALISMO PÚBLICO DA ADMINISTRAÇÃO DIRETA MUNICIPAL BRASILEIRA NA PERSPECTIVA DA DIMENSÃO POPULACIONAL
}

\section{CONCENTRATION OF PUBLIC SECTOR WORKERS IN DIRECT LOCAL ADMINISTRATION IN BRAZIL IN THE PERSPECTIVE OF THE POPULATION DIMENSION}

\begin{abstract}
Luci Nychai ${ }^{1}$
Amália Maria Goldberg Godoy ${ }^{2}$

Maria Luzia Lombat ${ }^{3}$

\section{RESUMO}

Apesar das recorrentes críticas ao aumento dos gastos do funcionalismo público, o Município é uma organização, e como tal depende do quadro de servidores da administração direta para poder funcionar e atender às demandas institucionais, sociais e econômicas como Ente Subnacional Federativo. A intenção deste artigo é apresentar a densidade do funcionalismo público municipal no Brasil a partir da dimensão populacional. A metodologia considerou os dados de corte observados para 2011 e agregados por municípios conforme o porte populacional e por grandes regiões geográficas. A análise complementar sobre o gasto com pessoal e encargos foi subsidiada pela utilização da proxy do Índice Firjan de Gestão Municipal para Gasto com Pessoal e das despesas municipais com pessoal do Finbra. Conforme os resultados, o gasto com funcionalismo público da administração direta municipal absorveu em média 40,82\% da receita corrente, sendo que apenas 7,97\% dos municípios brasileiros apresentam excelente condição na gestão do gasto com pessoal, abrangendo principalmente os pequenos municípios.
\end{abstract}

Palavras-chave: Funcionalismo público municipal; Administração direta; Densidade; Dimensão populacional.

\begin{abstract}
Despite recurring criticism of the increasing cost of public sector workers, a Town is an organization, and as such it depends on its civil servants in order to function and meet institutional, social and economic demands in its role as a sub-federal unit. This article aims to investigate the concentration of local civil service workers in Brazil in terms of the population dimension. The methodology took into account the data for 2011 and the aggregate data of towns in accordance with the size of their population and over large geographical regions. The complementary analysis of the expenditure required for staff and the positions the workers occupy was aided by the use of the proxy of the Firjan Fiscal Management Index for local management in terms of staff expenditure and local expenditure on Finbra staff. According to the results, civil service expenditure on direct administration of a town requires on average $40.82 \%$ of current revenue, with only $7.97 \%$ of Brazilian towns providing excellent management of staff expenditure. These towns mainly include the smaller towns.
\end{abstract}

Key words: Local civil service; Direct administration; Concentration; Population dimension.

Recebido 08/05/2013; Aceito 28/06/2013

\footnotetext{
${ }^{1}$ Professora do Departamento de Economia da Universidade Estadual do Centro-Oeste (UNICENTRO). E-mail: nychai@ibest.com.br.

2 Professora do Programa de Pós-Graduação em Economia da Universidade Estadual de Maringá (UEM). Email: amggodoy@uem.br.

${ }^{3}$ Doutoranda do Programa Pós-Graduação em Economia da Universidade Estadual de Maringá (UEM). E-mail: lombatl@terra.com.br.
} 


\section{Introdução}

Somado ao incremento paulatino das novas tecnologias e à diversidade de recursos materiais inseridos nas organizações públicas, o servidor configura as habilidades e competências necessárias à atuação eficiente, eficaz e efetiva da gestão pública municipal. $\mathrm{O}$ Município, em sua institucionalidade federativa, exerce a função mais próxima do cidadão no atendimento às incumbências constitucionais, sociais e econômicas, delegadas ao governo local. Para tanto, o quadro de pessoal da administração direta municipal é a engrenagem que faz o ente subnacional funcionar. A máquina administrativa local, para além dos fatores políticos e fiscais, está atrelada à dimensão populacional do Município. Neste sentido, pressupõe que o governo local tem a magnitude de capital humano relacionado à dimensão da população governada. Contudo, as restrições institucionais tendem a controlar essa relação, por isso é importante conhecer o comportamento da alocação de servidores municipais com a finalidade de distinguir a participação da dimensão populacional e da própria restrição institucional imposta por meio, por exemplo, da Lei de Responsabilidade Fiscal (LRF).

Portanto, este artigo objetiva apresentar as estimativas da densidade do funcionalismo público da administração direta dos municípios brasileiros a partir da perspectiva da dimensão populacional agregada pelas Grandes Regiões. O trabalho está estruturado de forma a apresentar uma síntese teórica sobre o tema e um cenário sobre as densidades do funcionalismo municipal, bem como uma abordagem complementar sobre o gasto municipal com pessoal e encargos.

\section{O funcionalismo público na Nova Administração Pública Municipal}

As discussões macroeconômicas sobre funcionalismo público, em qualquer nível de governo, remetem, quase sempre, às questões sobre o tamanho do Estado e à necessidade do ajuste fiscal com base no corte das despesas correntes e elevação dos investimentos, com efeitos positivos sobre o crescimento econômico. Rocha (2006), por exemplo, ressaltou a necessidade de um ajuste fiscal com corte das despesas correntes e aumento dos investimentos, defendendo que existe uma relação positiva entre o investimento público e o crescimento do PIB no longo prazo. O autor afirmou que essa relação não se confirma ou é negativa quando se tratam de gastos públicos correntes. Dessa forma, sugere a redução da participação do setor público na economia, com o intuito de abrir espaço para o setor privado e a elevação das taxas de crescimento no Brasil.

Rocha (2006) destacou ainda que, concomitantemente ao crescente aumento das despesas correntes, é importante observar que o tamanho e a participação do Estado na economia também cresceram. Porém, conforme argumentam Arvate e Biderman (2006), os casos em que o Estado deve interferir na economia são aqueles que estabelecem parâmetros orientadores e que, de forma adequada, estabelecem propostas de enxugamento da máquina pública. De acordo com os autores, um Estado mais eficiente não é necessariamente um Estado mínimo, mas aquele que investe parcela dos recursos públicos em áreas cuja ação é mais necessária, inclusive complementando a economia de mercado.

Especificamente no caso deste artigo, o foco do Estado mínimo está na representação subnacional do governo municipal e na relação do quadro de pessoal da administração direta com a dimensão populacional, sem, contudo, entrar no mérito da magnitude do Estado mínimo ideal no que tange ao contingente do quadro de pessoal da administração direta municipal, mas levando em consideração que o governo, de acordo com as atribuições que 
lhes são conferidas, deve representar e atender os anseios do Estado, atuando estrategicamente e de modo planejado para o bem público (SILVA; BASSI, 2012).

Na segunda metade do século XX, surgiram novos entendimentos sobre a gestão pública, a exemplo da Revolução Gerencial (MARTINS, 1997) ou da Nova Administração Pública (FERLIE et al., 1999). Para Bresser Pereira (2008), esse movimento surgiu para dar conta do modelo de reforma da gestão pública chamado de "modelo estrutural de gerência pública" na medida em que, além de grandes mudanças no processo de gestão de pessoal e da adoção de uma administração por objetivos, inclui a reforma estrutural da organização do Estado. O modelo estrutural de gerência pública inclui um aspecto organizacional ou estrutural e um aspecto gerencial ou de responsabilização. De um lado está o problema de como estruturar ou organizar os serviços do Estado, relacionado ao núcleo estratégico; de outro, está a questão de como administrar todo o sistema relacionado ao processo, gerência e estrutura.

Para a CNM (2008), a Administração Pública Gerencial tem sido questionada como solução hegemônica de um modelo de gestão eficiente para todos os níveis da administração pública. A implantação de algumas medidas que fazem parte da denominada Nova Administração Pública (NAP) ou Administração Pública Gerencial (APG), na intenção da busca de melhoria dos níveis de eficiência, acabam, paradoxalmente, afetando, na direção oposta, os objetivos pretendidos.

Segundo FERLIE et al. (1999), a NAP é um modelo de administração pública voltado à eficiência, eficácia e efetividade do aparelho do Estado, com foco em resultados, para o qual identificam quatro modelos de gestão denominados: i) impulso para a eficiência; ii) downsizing e descentralização; iii) em busca da excelência; e iv) orientação para o serviço público.

Guimarães e Silva (2000) ressaltaram que os modelos da NAP descritos por Ferlie et al. (1999) não são mutuamente exclusivos, devendo ser interpretados de forma contínua, que vai da racionalidade economicista e burocrática do modelo voltado para a eficiência à valorização da cidadania do modelo orientado para o serviço público. O Quadro 1 mostra o diagrama dessa visão de interação-concatenada, no qual o eixo vertical representa a tendência à eficiência e à racionalidade, que são características da formalidade, e no eixo horizontal, o desenvolvimento e a cidadania, conceitos ligados à prestação de serviços pela Administração Pública para o desenvolvimento do cidadão como ser social.

QUADRO 1 - Diagrama da visão de interação concatenada da NAP

\begin{tabular}{|l|l|l|}
\hline & \multicolumn{2}{|c|}{ Desenvolvimento e cidadania } \\
\hline \multirow{2}{*}{$\begin{array}{l}\text { Eficiência e } \\
\text { Racionalidade }\end{array}$} & Downsizing e Descentralização & Em busca da Excelência \\
\cline { 2 - 3 } & Impulso para a Eficiência & $\begin{array}{l}\text { Orientação para o Serviço } \\
\text { Público }\end{array}$ \\
\hline
\end{tabular}

Fonte: Adaptado de Guimarães e Silva (2000).

As mudanças no modelo de gestão, influenciadas pelas tendências do Estado mínimo, acabaram repercutindo diretamente nos municípios brasileiros. Para o CNM (2008), todo o Estado, incluindo-se aí sociedades, níveis de governos e todos os agentes responsáveis pela Administração Pública, sofrem os impactos dessas mudanças na medida em que é essencial para a sustentabilidade fiscal buscar a eficiência para utilizar melhor os recursos públicos. A cada dia, a sociedade tem um olhar mais aprimorado no controle social do setor público. Esse 
movimento repercute na gestão dos Municípios, mais especificamente no controle dos recursos públicos municipais e, consequentemente, na necessidade de mudança de seus modelos de gestão, buscando atender aos níveis de eficiência, eficácia e efetividade.

Draibe (2001) e Januzzi $(2002,2006)$ apontam que a eficiência é a capacidade de selecionar e usar os meios efetivos e de menor desperdício a fim de realizar uma tarefa ou um propósito. É a relação entre os custos e os produtos obtidos. A eficácia diz respeito ao alcance de objetivos e metas, ou seja, do resultado ou da mudança pretendida em uma dada realidade, em determinado tempo, dependentemente dos recursos envolvidos. Por fim, efetividade é a real contribuição em termos de retornos ao alcance da finalidade de uma intervenção ou do impacto de desenvolvimento esperado. Diz respeito à obtenção da maior quantidade/qualidade de impactos positivos e do menor número dos impactos negativos.

Na gestão pública, a eficiência, eficácia e efetividade condicionam o desempenho do governo local no exercício das funções. De acordo com Neely et al. (1995), o objetivo geral de um indicador de desempenho é conduzir a organização à melhoria de suas atividades, alinhadas ao ambiente institucional e aos objetivos estratégicos, de forma a permitir o monitoramento da gestão. Neste sentido, as informações que indiquem, parametrizem, avaliem o desempenho são relevantes para balizar a condução governativa pautada em ambientes, institucionais, político e econômico, múltiplos nos quais se inserem os Municípios brasileiros. O índice de gestão fiscal do gasto com pessoal da Firjan (2012b) e a densidade do funcionalismo público da administração direta municipal são exemplos de informações balizadores da gestão municipal. Segundo Pascarelli Filho (2011), a preocupação dos dirigentes do governo com o quadro do funcionalismo deve ser permanente no sentido de monitorar e confrontar os indicadores, selecionar no mercado aqueles cujo perfil melhor se enquadrada às demandas e tomando decisões quanto à alocação se servidores de acordo com as necessidades e que representem ganhos efetivos na qualidade e no retorno dos serviços prestados.

No contexto da Pesquisa de Informações Básicas Municipais (MUNIC) do IBGE (2012), a administração pública direta municipal é aquela exercida diretamente pelas secretarias, departamentos e outros órgãos, enquanto a administração pública indireta é exercida por pessoas jurídicas de autarquias, fundações públicas, empresas públicas, sociedades de economia mista e associações públicas. Sendo que na administração direta os vínculos empregatícios do pessoal ocupado compreendem as seguintes categorias: i) estatutário; ii) celetistas; iii) comissionados; iv) estagiários; e v) sem vínculo permanente.

O servidor estatutário caracteriza o funcionário contratado sob o Regime Jurídico Único (RJU). O celetista é o funcionário contratado pela prefeitura sob o regime da Consolidação das Leis Trabalhistas (CLT), admitido após teste seletivo para um contrato de tempo determinado. A categoria sem vínculo permanente caracteriza o funcionário que trabalha por prestação de serviço, sem vínculo empregatício e sem carteira de trabalho assinada. Também são incluídos nesta categoria os autônomos, voluntários e aqueles cedidos por outras administrações. Os estagiários são servidores em fase de aprendizado que abrangem os estudantes frequentando o ensino regular, em instituições de educação superior, de educação profissional, de ensino médio, da educação especial e dos anos finais do ensino fundamental, na modalidade profissional da educação de jovens e adultos. O funcionário comissionado é aquele que tem como vínculo apenas o cargo comissionado que exerce na gestão pública municipal (IBGE, 2012).

De acordo com Santos (2006), a gestão pública refere-se às funções de gerência pública dos negócios do governo. Já a administração pública, segundo Silva (2008), envolve a 
ação do administrador público em três níveis: i) atos de governo, que se situam no contexto político; ii) atos de administração, atividade neutra, vinculada à lei; e iii) atos de gestão, que compreendem os seguintes parâmetros básicos: a) compreensão e assimilação da missão; b) realização de planejamento e controle; c) administração dos recursos humanos, materiais, tecnológicos e financeiros; d) inserção de cada unidade organizacional no foco da organização; e) tomada de decisão diante de conflitos internos e externos.

\section{Configuração metodológica}

Este artigo abrange três análises: uma considerada básica e duas complementares. A básica refere-se à estimação da densidade do funcionalismo público municipal agregado por dimensão populacional e Grandes Regiões; na complementar inserem-se as análises da gestão fiscal de pessoal por meio do Índice Firjan de Gestão Fiscal (FIRJAN, 2012a) do Gasto com Pessoal e a análise do gasto municipal com pessoal e encargos agregado por Unidade da Federação (UF), a partir dos dados da base do FINBRA para o ano de 2011 (FINBRA, 2013).

\subsection{Densidade do funcionalismo público municipal (DFPM) agregado por dimensão populacional}

Na Física, a densidade ou massa volumétrica de um corpo define-se como o quociente entre a massa e o volume desse corpo. Desta forma, pode-se dizer que a densidade mede o grau de concentração de massa em determinado volume (HOLZNER, 2009). Por analogia, a densidade do funcionalismo público municipal (DFPM) mede a concentração de servidores da administração direta municipal por mil habitantes.

Para estimação da DFPM, considerou-se os dados de corte para os Municípios brasileiros observados na Pesquisa de Informações Básicas Municipais do IBGE para o quadro de pessoal e a dimensão populacional por Grande Região para o ano de 2011.

Para a dimensão populacional, foram consideradas as seguintes faixas de agregação por habitantes: i) Até 5.000; ii) de 50.001 a 20.000; iii) de 20.001 a 100.000 ; iv) 100.001 a 500.000; e v) Mais de 500.001.

As dimensões populacionais foram consideradas para o espaço geográfico das Grandes Regiões brasileiras: Norte, Nordeste, Sudeste, Sul e Centro-Oeste.

Para fins deste artigo, foram consideradas as seguintes categorias de vínculo empregatício na administração direta municipal: i) Estatutário; ii) Celetista; iii) Comissionado; iv) Estagiário; e v) Sem vínculo permanente.

DFPM/1.000 hab. em cada categoria de vínculo empregatício é dada por:

$$
D F P M=\left[\left(\sum_{m=1}^{n} F_{m i j} / \sum_{m=1}^{n} P_{m i j}\right) * 1000\right]
$$

Em que:

$\mathrm{F}=$ Funcionalismo público municipal da administração direta.

$\mathrm{P}=$ População total. 


$$
\begin{aligned}
& n=\text { universo de municípios. } \\
& m=\text { Número de municípios por dimensão populacional. } \\
& i=\text { Dimensão populacional ( } 5 \text { dimensões). } \\
& j=\text { Grandes regiões ( } 5 \text { regiões). }
\end{aligned}
$$

A média absoluta de funcionários públicos da administração direta (MAFPM) por município é mensurada pela razão entre o total do funcionalismo $(F)$ em determinada dimensão $(i)$ de uma Grande Região $(j)$ pelo total de municípios $(M)$ daquela dimensão populacional regional:

$$
M A F P M=\left[\left(\sum_{m i j=1}^{n} F_{m i j} / \sum_{i j=1}^{n} M_{i j}\right)\right]
$$

\subsection{Análises complementares}

\subsubsection{Desempenho municipal da gestão do gasto com pessoal}

Foram empregadas as funções da estatística descritiva, tais como: razões matemáticas desvio-padrão (DP), média aritmética (MA) e coeficiente de variação (CV).

O CV identifica a maior ou menor diversificação relativa dos valores de uma variável em torno de uma tendência central, no caso a média. Acima de $30 \%$, o CV é considerado alto, ou seja, há uma maior heterogeneidade entre os dados analisados em relação a sua média. $\mathrm{O}$ coeficiente de variação é dado por: $\mathrm{CV}=[(\mathrm{DP} / \mathrm{MA}) * 100]$. Os resultados foram mostrados por meio de um radar de dispersão.

Considerou-se como proxy da gestão municipal do gasto com pessoal, o Índice Firjan de Gestão Municipal nesta categoria, o qual mede, por meio de uma escala de 0 a 1 , o desempenho dos Municípios. De acordo com a Firjan (2012b), quanto mais próximo de 1 for o indicador, menor será o comprometimento do orçamento com a folha de salários do funcionalismo municipal e, consequentemente, maior o espaço de manobra para a prefeitura programar políticas públicas.

\subsubsection{Média mensal de gasto municipal com pessoal e encargos sociais com pessoal}

Para esta análise complementar, foram utilizados os gastos com pessoal e encargos da administração direta dos Municípios brasileiros coletados no relatório das informações sobre despesas e receitas de cada município brasileiro, divulgadas pela Secretaria do Tesouro Nacional (FINBRA, 2013).

Os resultados foram calculados de forma a estimar o comportamento do gasto médio com pessoal e encargos sociais por Município (GMPEM) agregado por UF e Grande Região para o valor em $\mathrm{R} \$ 1,00$, correspondente a um funcionário por mês. 


$$
G M P E M=\left\{\left[\frac{\left(\sum_{m=1}^{n} G P E_{m i j} / \sum_{i=1}^{n} M U_{i j}\right)}{M A F P_{j}}\right] / 12\right\}
$$

Em que:

$\mathrm{GPE}=$ Gasto público municipal com pessoal e encargos (em $\mathrm{R} \$ 1,00)$.

$\mathrm{MU}=$ Número de municípios da amostragem do Finbra.

MAFP $=$ Média do funcionalismo público municipal.

$n=$ Universo de municípios.

$m=$ Município, $i=$ Estado e $j=$ Grande Região

Ressalta-se que, nessa estimativa, para a média do funcionalismo público por UF, foi considerada a média da Grande Região cujo estado está inserido.

\section{Discussão dos resultados}

\subsection{O desempenho da gestão do gasto com pessoal dos Municípios brasileiros}

Com o objetivo de propiciar maior grau de manobra do gestor público com relação à alocação de recursos em outras funções de despesas e conter o desequilíbrio orçamentário, a Lei de Responsabilidade Fiscal (LRF) $\mathrm{n}^{\circ}$ 101, de 2000, restringiu os gastos com pessoal dos Municípios em até $60 \%$ da Receita Corrente Líquida (RCL). Além do que o seu Artigo 22 elegeu um limite segurança correspondente a $95 \%$ do teto, ou seja, $57 \%$, acima do qual se limitam as criações de vagas, cargos ou funções (BRASIL, 2000).

Segundo a LRF (BRASIL, 2000), a despesa com pessoal é um agregado de doze meses de dispêndios compromissados (empenhados) com salários, aposentadorias, pensões, salário-família dos servidores, obrigações patronais, entre outros elementos de despesa. $\mathrm{O}$ artigo 18 da LRF detalhou o gasto com pessoal como uma despesa de caráter remuneratória decorrente do exercício do emprego, cargo ou função de confiança no setor público e das consequentes obrigações, contribuições, gratificações, adicionais e outros direitos remuneratórios e, ainda, despesas com contratações temporárias para atender à necessidade excepcional de interesse público e despesas com contratos de terceirização de mão de obra.

A análise do desempenho da gestão do gasto com pessoal foi realizada por meio do Índice Firjan de Gestão Municipal para o Gasto com Pessoal (IFGM-Gasto com Pessoal). A Tabela 1 apresenta a estatística descritiva da avaliação de desempenho da gestão do gasto público dos Municípios brasileiros agregado por Unidade Federativa (UF). 
TABELA 1 - Qualidade da gestão do gasto com pessoal dos Municípios brasileiros

\begin{tabular}{c|c|c|c|c}
\hline UF & $\begin{array}{c}\text { IFGF gastos com } \\
\text { pessoal (médio) }\end{array}$ & Desvio-padrão & $\begin{array}{l}\text { Amostra de } \\
\text { municípios }\end{array}$ & $\begin{array}{l}\text { Coeficiente } \\
\text { de variação } \\
(\boldsymbol{\%})\end{array}$ \\
\hline RS & 0,6859632 & 0,127788 & 494 & 18,63 \\
\hline TO & 0,6737246 & 0,150319 & 134 & 22,31 \\
\hline PR & 0,6705204 & 0,11735 & 387 & 17,50 \\
\hline SC & 0,6573481 & 0,103107 & 291 & 15,69 \\
\hline SP & 0,6300771 & 0,147364 & 629 & 23,39 \\
\hline RJ & 0,6207071 & 0,178308 & 84 & 28,73 \\
\hline MT & 0,6152197 & 0,154453 & 137 & 25,11 \\
\hline MS & 0,6141013 & 0,12505 & 77 & 20,36 \\
\hline RR & 0,6038083 & 0,33373 & 12 & 55,27 \\
\hline MG & 0,5747709 & 0,139055 & 820 & 24,19 \\
\hline ES & 0,5747143 & 0,172814 & 77 & 30,07 \\
\hline BA & 0,5734299 & 0,183759 & 374 & 32,05 \\
\hline RO & 0,5669327 & 0,11155 & 52 & 19,68 \\
\hline CE & 0,5624542 & 0,168932 & 179 & 30,03 \\
\hline GO & 0,5617969 & 0,197332 & 224 & 35,13 \\
\hline AM & 0,5501098 & 0,210578 & 51 & 38,28 \\
\hline PI & 0,546348 & 0,207152 & 196 & 37,92 \\
\hline MA & 0,5449706 & 0,226345 & 194 & 41,53 \\
\hline AC & 0,5067381 & 0,187628 & 21 & 37,03 \\
\hline RN & 0,5042538 & 0,249786 & 156 & 49,54 \\
\hline PA & 0,4631202 & 0,254076 & 109 & 54,86 \\
\hline SE & 0,4219162 & 0,282708 & 74 & 67,01 \\
\hline AL & 0,4185165 & 0,249251 & 91 & 59,56 \\
\hline AP & 0,3927846 & 0,296407 & 13 & 75,46 \\
\hline PB & 0,3518986 & 0,283972 & 211 & 80,70 \\
\hline PE & 0,3206665 & 0,269451 & 179 & 84,03 \\
\hline Fon & & & \\
\hline
\end{tabular}

Fonte: Elaborado pelas autoras conforme Firjan (2012).

De acordo com a FIRJAN (2012b), esse indicador avalia o comprometimento das receitas dos Municípios com as despesas com pessoal numa escala de 0 a 1 . O desempenho médio da gestão do gasto com pessoal dos Municípios brasileiros para o recorte de 2010 é considerado, de acordo com a classificação da FIRJAN (2012b), "em dificuldade" com uma magnitude de 0.54642 e alta variabilidade, conforme o coeficiente de variação de $39,38 \%$. Os Municípios que apresentaram "boas condições" da gestão nesta categoria totalizaram 42,63\%, dos quais 7,92\% estão em "excelentes condições". Os Municípios em boas condições estão localizados, respectivamente, nos Estados do Rio Grande do Sul, Tocantins, Paraná, Santa Catarina, São Paulo, Rio de Janeiro, Mato Grosso, Mato Grosso do Sul e Roraima. Os demais caracterizaram situação de "dificuldade", com desempenho abaixo de entre 0,4 a 0,6, e "crítico", abaixo de 0,4. Destaca-se que os oito primeiros Estados cujos Municípios apresentaram bom desempenho na gestão do gasto com pessoal também configuraram uma homogeneidade interna, isto é, apresentam desempenho homogêneo em relação à média; não ocorreu grande dispersão considerando o parâmetro do coeficiente de variação acima de $30 \%$. O que não acontece com as demais amostras de Municípios por Unidade Federativa. A Figura 
1 mostra o radar de dispersão da gestão do gasto com pessoal dos Municípios brasileiros agregados por Estados.

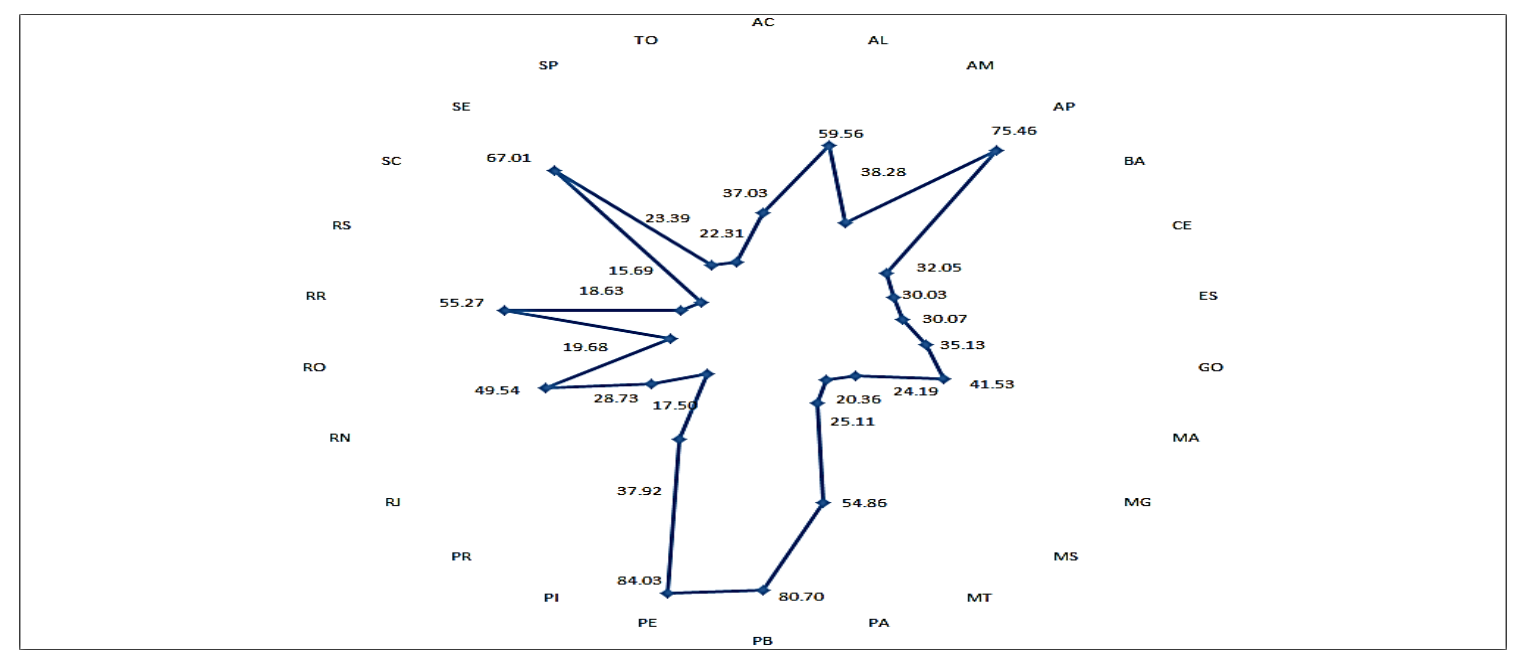

FIGURA 1 - Radar de dispersão da gestão do gasto com pessoal dos Municípios brasileiros agregados por Estados

Fonte: Elaborado pelas autoras.

O radar mostra que os Municípios localizados nos Estados de Pernambuco, Paraíba, Amapá, Sergipe, Alagoas e Roraima apresentaram grande dispersão, isto é, houve grande disparidade no desempenho entre eles em cada Estado. Ressalta-se em especial o caso de Roraima, cujos Municípios foram classificados com bom desempenho, mas apresentaram grande dispersão em relação à média. Em Roraima, poucas unidades com alto índices de qualidade neutralizaram os índices de baixo desempenho, o que proporcionou viés. Desta forma, é mais conveniente classificar os Municípios desta UF na condição de "dificuldade".

\subsection{Densidade do funcionalismo público municipal}

Nesta análise, a densidade tem a finalidade de quantificar o contingente do funcionalismo público nos Municípios brasileiros por mil habitantes a partir das faixas de dimensão populacional das grandes regiões geográficas brasileiras. A Tabela 2 contém os resultados da densidade agregados para o país.

TABELA 2 - Densidade do funcionalismo público municipal da administração direta por dimensão populacional 


\begin{tabular}{|c|c|c|c|c|c|c|c|c|}
\hline $\begin{array}{l}\text { Dimensão } \\
\text { populacional }\end{array}$ & $\begin{array}{l}\text { Média geral } \\
\text { absoluta do } \\
\text { funcionalismo } \\
\text { por município } \\
\text { (Funcionário } \\
\text { por } \\
\text { município) }\end{array}$ & 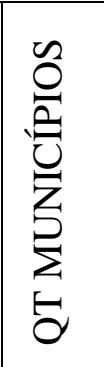 & 总 & 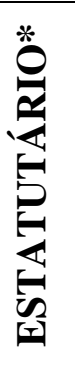 & 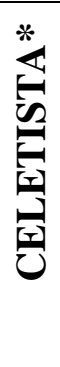 & $\begin{array}{l}0 \\
2 \\
2 \\
0 \\
0 \\
0 \\
0 \\
0 \\
0\end{array}$ & 包 & 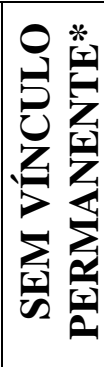 \\
\hline BRASIL & 1013 & 5565 & 30 & 19 & 3 & 3 & 1 & 5 \\
\hline Até 5.000 & 217 & 1301 & 65 & 43 & 6 & 8 & 1 & 8 \\
\hline De 5.001 a 10.000 & 351 & 1212 & 50 & 31 & 5 & 5 & 1 & 8 \\
\hline De 10.001 a 20.000 & 621 & 1401 & 45 & 27 & 4 & 4 & 1 & 8 \\
\hline De 20.001 a 50.000 & 2232 & 1043 & 39 & 24 & 4 & 3 & 1 & 7 \\
\hline De 50.001 a 100.000 & 1177 & 325 & 33 & 19 & 4 & 3 & 1 & 6 \\
\hline De 100.001 a 500.000 & 4797 & 245 & 24 & 14 & 3 & 2 & 1 & 4 \\
\hline Mais de 500.000 & 24510 & 38 & 17 & 13 & 1 & 1 & 1 & 2 \\
\hline
\end{tabular}

Fonte: Elaborado pelas autoras conforme Pesquisa de Informações Básicas Municipais do IBGE (2011).

Nota: * Densidade por 1.000/hab.

Considerando a dimensão populacional dos Municípios, a média encontrada foi de 1.013 servidores públicos por Município no Brasil na administração direta, configurando uma tendência esperada de média crescente, isto é, que aumenta de acordo com a dimensão populacional. A densidade do funcionalismo público Municipal (DFPM) foi de 30 servidores para cada mil habitantes, distribuídos nas categorias de estatutário (19 fun./hab.), celetista (3 fun./hab.), comissionado (3 fun./hab.), estagiário (1 fun./hab.) e sem vínculo permanente (5 fun./hab.). Observou-se que, para o recorte de 2011, a DFPM diminui na medida em que aumenta a dimensão populacional dos Municípios. Portanto, a densidade é maior para pequenos Municípios e menor para grandes Municípios. A Figura 2 mostra o comportamento das densidades a partir das dimensões populacionais. 


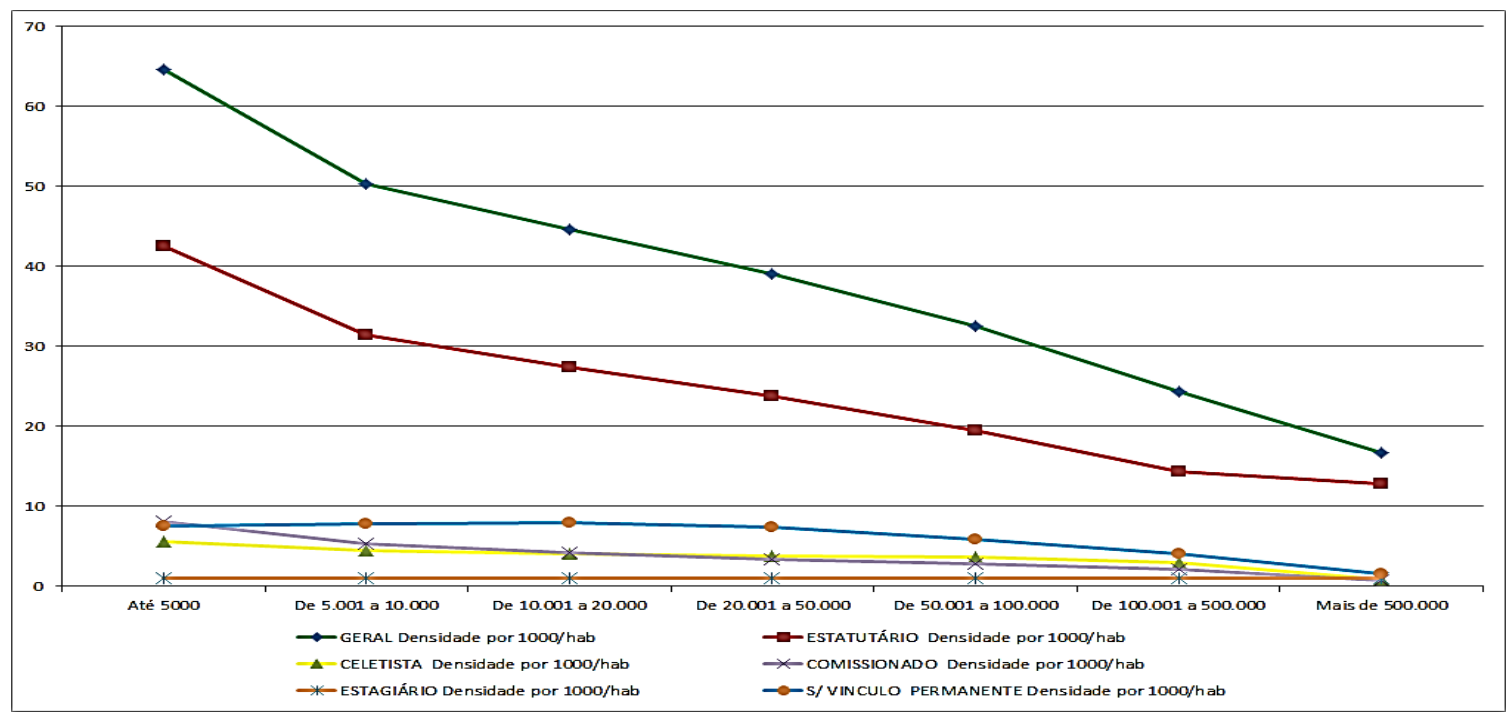

FIGURA 2 - Comportamento da DFPM por dimensão populacional para os Municípios brasileiros em 2011

Fonte: Elaborado pelas autoras.

A explicação para a relação inversa entre dimensão populacional e densidade do funcionalismo pode estar na magnitude da população em cada dimensão e na questão fiscalfinanceira. Apesar de o número de Municípios acima de 50 mil habitantes ser pequeno e representar apenas $11 \%$ do total, abrange $66,45 \%$ da população. O maior volume populacional e as diferenças das remunerações do funcionalismo público, somadas às restrições institucionais impostas, principalmente pela Lei de Responsabilidade Fiscal, corroboraram para que a densidade apresente uma relação inversa quanto ao tamanho populacional. Estima-se que nos municípios com até 20 mil habitantes, os quais absorveram $17,12 \%$ da população, os gastos com pessoal e encargos representou, em 2011, $29 \%$ do total dos gastos dos municípios brasileiros para esta função, para uma DFPM média de 53/1000 hab. Para os municípios com mais de 100 mil habitantes, os quais absorveram 54,75\% da população, o gasto na função de pessoal e encargos representou 38,7\% do total dos gastos dos municípios brasileiros para esta função, para uma DFPM média de 21 servidores por mil habitantes.

Medindo a sensibilidade DFPM do gasto com pessoal e encargos por meio da razão (\% gasto / DFPM), estima-se que, no primeiro caso, a sensibilidade é inelástica, ou seja, para cada aumento de 1 servidor por 1000/hab., o gasto aumentaria na ordem de 0,55\%. No segundo caso, a relação é elástica, na ordem de $1,84 \%$. Portanto, o aumento dos gastos com o funcionalismo público municipal por 1000/hab nos médios e grandes municípios é mais impactado que nos pequenos municípios.

A categoria do funcionalismo estatutário representou, em 2011, 65,06\% do quadro público de pessoal na administração direta dos municípios brasileiros. Os celetistas representaram 9,14\%, e os outros (estagiários, comissionários e sem vínculo permanente) representaram $25,92 \%$. A Tabela 3 mostra a comparação do funcionalismo municipal para os anos de 1999, 2002 e 2011. 
TABELA 3 - A proporção de servidores da Administração Direta por categoria no total de servidores dos Municípios: 1999, 2002 e 2011 (\%)

\begin{tabular}{|l|c|c|c|c|c|c|c|c|c|}
\hline Dimensão & \multicolumn{4}{|c|}{1999} & \multicolumn{3}{c|}{2002} & \multicolumn{3}{c|}{2011} \\
\hline Brasil & Estatutários & CLT & Outros & Estatutários & CLT & Outros & Estatutários & CLT & Outros \\
\hline Geral & $\mathbf{6 7 . 3 4}$ & $\mathbf{1 7 . 9 8}$ & $\mathbf{2 4 . 6 8}$ & $\mathbf{6 6 . 1 3}$ & $\mathbf{1 4 . 0 7}$ & $\mathbf{1 9 . 7 7}$ & $\mathbf{6 3 . 7 2}$ & $\mathbf{9 . 5 4}$ & $\mathbf{2 6 . 8 4}$ \\
\hline Até 5000 & 65,28 & 18,20 & 15,41 & 65,86 & 13,22 & 20,82 & 65.79 & 8.75 & 25.46 \\
\hline De 5001 a 20000 & 63,34 & 19,60 & 16,19 & 62,97 & 14,50 & 22,42 & 62.41 & 9.20 & 28.36 \\
\hline De 20001 a 100000 & 62,48 & 20,63 & 16,07 & 61,72 & 16,67 & 21,62 & 60.38 & $\begin{array}{c}10.3 \\
4\end{array}$ & 29.08 \\
\hline $\begin{array}{l}\text { De 100001 a } \\
\text { 500000 }\end{array}$ & 67,25 & 20,31 & 12,30 & 63,62 & 18,47 & 17,90 & 59.62 & $\begin{array}{c}12.1 \\
8\end{array}$ & 29.01 \\
\hline Mais de 500000 & 85,63 & 6,45 & 7,92 & 81,41 & 4,30 & 14,30 & 77.07 & 5.24 & 17.69 \\
\hline
\end{tabular}

Fonte: Elaborado pelas autoras, conforme IBGE (2003) e Pesquisa de Informações Básicas Municipais do IBGE (2011).

Considerando que o contingente de funcionalismo municipal estatutário em 2011 foi de 3,6 milhões, e comparando com os totais de 1999 e 2002, que foram, respectivamente, de 2,08 e 2,55 milhões, estimou-se um crescimento relativo no período 1999-2002 de 22,60\%, no período 2002-2011 de 40,87\% e no período de 1999-2011 de 72,70\%. Entretanto, apesar de o contingente absoluto de estatutários de 1999 a 2011 ter crescido, a sua representatividade relativa vem diminuindo gradativamente em todas as dimensões populacionais de municípios. O mesmo aconteceu com os celetistas. Mas na categoria "outros" houve um sensível crescimento em todas as dimensões. No caso dos municípios com mais de 100 mil habitantes, houve um aumento médio de 13,24\% em relação a 1999.

\subsection{Densidade do funcionalismo público municipal por grande região}

Esta análise proporciona uma visão sobre a densidade do funcionalismo público municipal para as dimensões populacionais a partir das grandes regiões: Norte, Nordeste, Sudeste, Sul e Centro-Oeste. O Quadro 2 contém as DFPM por 1000 habitantes. Em todas as grandes regiões, a densidade do funcionalismo público municipal da administração direta é mais alta nos municípios com até 10 mil habitantes, sendo que a Região Sul apresentou a menor densidade nessa dimensão populacional. Na categoria do funcionalismo estatutário, as regiões se mostraram homogêneas, à exceção do Centro-Oeste. Destaca-se que as maiores magnitudes na categoria sem vínculo permanente foram identificadas nas regiões Norte, Nordeste e Sudeste nos pequenos municípios e a menor na região Sul. 
QUADRO 2 - Densidade do funcionalismo público municipal por grande região

\begin{tabular}{|c|c|c|c|c|c|c|c|c|c|}
\hline CLASSE/REGIÃO & $\begin{array}{c}\text { Num de } \\
\text { Municípios } \\
\text { por classe }\end{array}$ & $\begin{array}{c}\text { População } \\
\text { total por } \\
\text { classe }\end{array}$ & \begin{tabular}{|c} 
Média de \\
funcionalismo por \\
Município dentro \\
da classe
\end{tabular} & $\begin{array}{c}\text { Densidade geral } \\
\text { do } \\
\text { funcionalismo* }\end{array}$ & $\begin{array}{c}\text { Densidade do } \\
\text { funcionalismo } \\
\text { Estatutário* }\end{array}$ & $\begin{array}{c}\text { Densidade do } \\
\text { funcionalismo } \\
\text { Celetista* }\end{array}$ & $\begin{array}{l}\text { Densidade do } \\
\text { funcionalismo } \\
\text { Comissionado* }\end{array}$ & $\begin{array}{c}\text { Densidade do } \\
\text { funcionalismo } \\
\text { Estagiário* }\end{array}$ & $\begin{array}{c}\text { Densidade do } \\
\text { funcionalismo } \\
\text { sem vinculo } \\
\text { permanente* }\end{array}$ \\
\hline BRASIL & 5565 & 190755799 & 1013 & 30 & 19 & 3 & 3 & 1 & 5 \\
\hline Até 5.000 & 1301 & 4374345 & 217 & 65 & 43 & 6 & 8 & 1 & 8 \\
\hline De 5.001 a 10.000 & 1212 & 8541935 & 351 & 50 & 31 & 5 & 5 & 1 & 8 \\
\hline De 10.001 a 20.000 & 1401 & 19743967 & 621 & 45 & 27 & 4 & 4 & 1 & 8 \\
\hline De 20.001 a 50.000 & 1043 & 31344671 & 1177 & 39 & 24 & 4 & 3 & 1 & 7 \\
\hline De 50.001 a 100.000 & 325 & 22314204 & 2232 & 33 & 19 & 4 & 3 & 1 & 6 \\
\hline De 100.001 a 500.000 & 245 & 48565171 & 4797 & 25 & 14 & 3 & 2 & 1 & 4 \\
\hline Mais de 500.000 & 38 & 55871506 & 24510 & 17 & 13 & 1 & 1 & 1 & 2 \\
\hline NORTE & 449 & 15864454 & 1148 & 33 & 20 & 2 & 3 & 1 & 8 \\
\hline Até 5.000 & 86 & 280503 & 209 & 65 & 43 & 1 & 9 & 1 & 11 \\
\hline De 5.001 a 10.000 & 81 & 594875 & 371 & 51 & 31 & 3 & 6 & 1 & 11 \\
\hline De 10.001 a 20.000 & 108 & 1553000 & 643 & 46 & 26 & 3 & 5 & 1 & 10 \\
\hline De 20.001 a 50.000 & 111 & 3364656 & 2558 & 42 & 24 & 2 & 3 & 1 & 12 \\
\hline De 50.001 a 100.000 & 43 & 2919449 & 1242 & 39 & 23 & 2 & 3 & 1 & 9 \\
\hline De 100.001 a 500.000 & 18 & 3956558 & 5739 & 27 & 16 & 1 & 3 & 1 & 7 \\
\hline Mais de 500.000 & 2 & 3195413 & 23362 & 16 & 10 & 1 & 1 & 1 & 3 \\
\hline NORDESTE & 1794 & 53081950 & 1025 & 35 & 22 & 2 & 3 & 1 & 7 \\
\hline Até 5.000 & 241 & 880565 & 255 & 71 & 43 & 5 & 11 & 1 & 10 \\
\hline De 5.001 a 10.000 & 363 & 2586859 & 402 & 57 & 36 & 3 & 7 & 1 & 10 \\
\hline De 10.001 a 20.000 & 591 & 8394057 & 715 & 51 & 32 & 2 & 5 & 1 & 11 \\
\hline De 20.001 a 50.000 & 428 & 12572502 & 2314 & 44 & 28 & 2 & 4 & 1 & 10 \\
\hline De 50.001 a 100.000 & 113 & 7455612 & 1281 & 36 & 21 & 3 & 3 & 1 & 8 \\
\hline De 100.001 a 500.000 & 47 & 8465330 & 4672 & 28 & 14 & 2 & 3 & 1 & 8 \\
\hline Mais de 500.000 & 11 & 12727025 & 16402 & 14 & 10 & 1 & 1 & 1 & 1 \\
\hline SUDESTE & 1668 & 80364410 & 1224 & 26 & 16 & 4 & 2 & 1 & 3 \\
\hline Até 5.000 & 398 & 1370912 & 234 & 68 & 42 & 11 & 5 & 1 & 10 \\
\hline De 5.001 a 10.000 & 391 & 2750485 & 351 & 51 & 28 & 8 & 4 & 1 & 9 \\
\hline De 10.001 a 20.000 & 356 & 4986619 & 571 & 41 & 23 & 8 & 3 & 1 & 6 \\
\hline De 20.001 a 50.000 & 285 & 8763842 & 2230 & 37 & 19 & 8 & 3 & 1 & 6 \\
\hline De 50.001 a 100.000 & 99 & 7028740 & 1144 & 31 & 17 & 6 & 2 & 1 & 4 \\
\hline De 100.001 a 500.000 & 122 & 24908047 & 4881 & 24 & 14 & 4 & 2 & 1 & 3 \\
\hline Mais de 500.000 & 17 & 30555765 & 27322 & 16 & 12 & 1 & 1 & 1 & 1 \\
\hline SUL & 1188 & 27386891 & 637 & 28 & 19 & 3 & 2 & 2 & 2 \\
\hline Até 5.000 & 433 & 1369243 & 176 & 56 & 40 & 3 & 7 & 2 & 4 \\
\hline De 5.001 a 10.000 & 273 & 1886642 & 274 & 40 & 28 & 3 & 4 & 2 & 3 \\
\hline De 10.001 a 20.000 & 234 & 3227631 & 478 & 35 & 23 & 4 & 3 & 2 & 2 \\
\hline De 20.001 a 50.000 & 147 & 4430505 & 1739 & 31 & 21 & 4 & 2 & 2 & 2 \\
\hline De 50.001 a 100.000 & 53 & 3655245 & 943 & 26 & 18 & 3 & 2 & 2 & 2 \\
\hline De 100.001 a 500.000 & 44 & 8634378 & 4299 & 22 & 15 & 2 & 1 & 2 & 2 \\
\hline Mais de 500.000 & 4 & 4183247 & 18584 & 19 & 14 & 1 & 1 & 1 & 3 \\
\hline \begin{tabular}{|l|} 
CENTRO-OESTE \\
\end{tabular} & 466 & 11487934 & 1041 & 43 & 31 & 1 & 5 & 1 & 6 \\
\hline Até 5.000 & 143 & 473122 & 237 & 73 & 51 & 1 & 14 & 1 & 6 \\
\hline De 5.001 a 10.000 & 104 & 723074 & 356 & 52 & 35 & 2 & 9 & 1 & 6 \\
\hline De 10.001 a 20.000 & 112 & 1582660 & 568 & 41 & 28 & 2 & 5 & 1 & 5 \\
\hline De 20.001 a 50.000 & 72 & 2213166 & 2408 & 35 & 24 & 1 & 5 & 1 & 4 \\
\hline De 50.001 a 100.000 & 17 & 1255158 & 1061 & 34 & 21 & 1 & 5 & 1 & 6 \\
\hline De 100.001 a 500.000 & 14 & 2600858 & 4832 & 27 & 16 & 1 & 4 & 1 & 5 \\
\hline Mais de $500.000 \mathrm{C} / \mathrm{DF}$ & 4 & 5210056 & 41357 & 33 & 26 & 1 & 1 & 1 & 4 \\
\hline
\end{tabular}

Fonte: Elaborado pelas autoras conforme dados da Pesquisa de Informações Básicas Municipais do IBGE (2011).

Nota: *Por 1.000 habitantes.

A região Centro-Oeste apresentou a maior DFPM (43 func./1.000 hab.), e a região Sudeste (26 func./1.000 hab.) mostrou a menor densidade, seguida da região Sul (28 func./1.000 hab.), na categoria geral em relação às demais regiões. A Figura 3 mostra uma síntese do comportamento de cada grande região com relação às DFPMs médias por categoria de servidor público. 


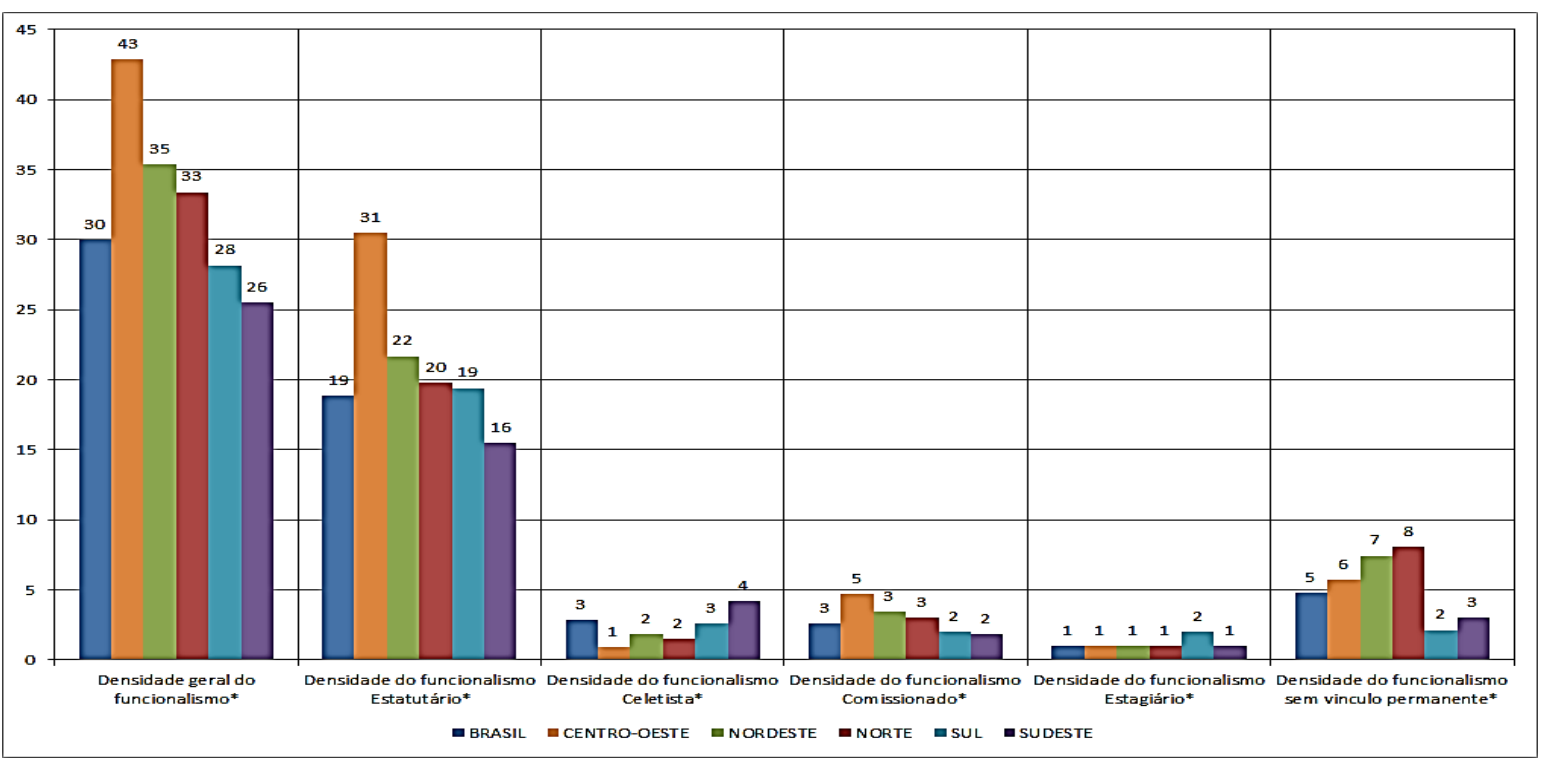

FIGURA 3 - Densidades do funcionalismo público municipal por categoria de servidor público nas grandes regiões

Fonte: Elaborado pelas autoras conforme dados da Pesquisa de Informações Básicas Municipais do IBGE (2011).

Nota: * Por 100 habitantes.

A região Centro-Oeste apresentou a maior densidade no quadro geral, influenciada pelas categorias de estatutário comissionado. Dois fatores influenciaram esse cenário: a alta densidade do funcionalismo nos municípios de até 5.000 habitantes e a presença do Distrito Federal como unidade acima de 500 mil habitantes. Com relação às categorias comissionados e sem vínculo permanente, as regiões Sul e Sudeste caracterizaram as menores DFPMs.

Esses indicadores referem-se à administração direta municipal de 2011, a qual trabalhou com um contingente de 5,6 milhões de servidores distribuídos em todas as categorias. A administração indireta municipal envolveu, em 2011, 0,4 milhões de funcionários. Considerando a população brasileira para o ano, estima-se que 3,49\% estavam ocupados nos quadros do funcionalismo da administração direta dos municípios, representando aproximadamente $\mathrm{R} \$ 145$ bilhões. A Figura 4 apresenta o comportamento do gasto médio com pessoal e encargos sociais por município agregado por UF e Grande Região para o valor em $\mathrm{R} \$ 1,00$ corresponde a um funcionário por mês.

A média do gasto com pessoal e encargos sociais da administração direta estimada para os municípios brasileiros a partir das Grandes Regiões foi de R\$ 2.212,01. O comportamento apresentado pelos municípios agregados por estados e regiões identificou um nível alto de dispersão entre eles, cujos coeficientes de variação (CV) estimados ficaram acima do parâmetro de 30\%. Dois extremos merecem destaque, a Região Sudeste, com um CV de 99,40\%, caracterizando altíssima variabilidade entre os municípios agregados por UF e, no outro extremo, a Região Sul, com um CV de 2,17\%, representando dispersão muito pequena. No caso da Região Sudeste, os municípios do estado do Rio de Janeiro puxaram a média do gasto com pessoal e encargos sociais para cima. No caso da Região Sul, os municípios nos estados do Paraná, Santa Catarina e Rio Grande do Sul apresentaram o mesmo comportamento, isto é, quase não houve diferença significativa nas médias do dispêndio com 
pessoal e encargos sociais, configurando a menor média na comparação com as outras grandes regiões, ou seja, $\mathrm{R} \$ 1.353,69$.

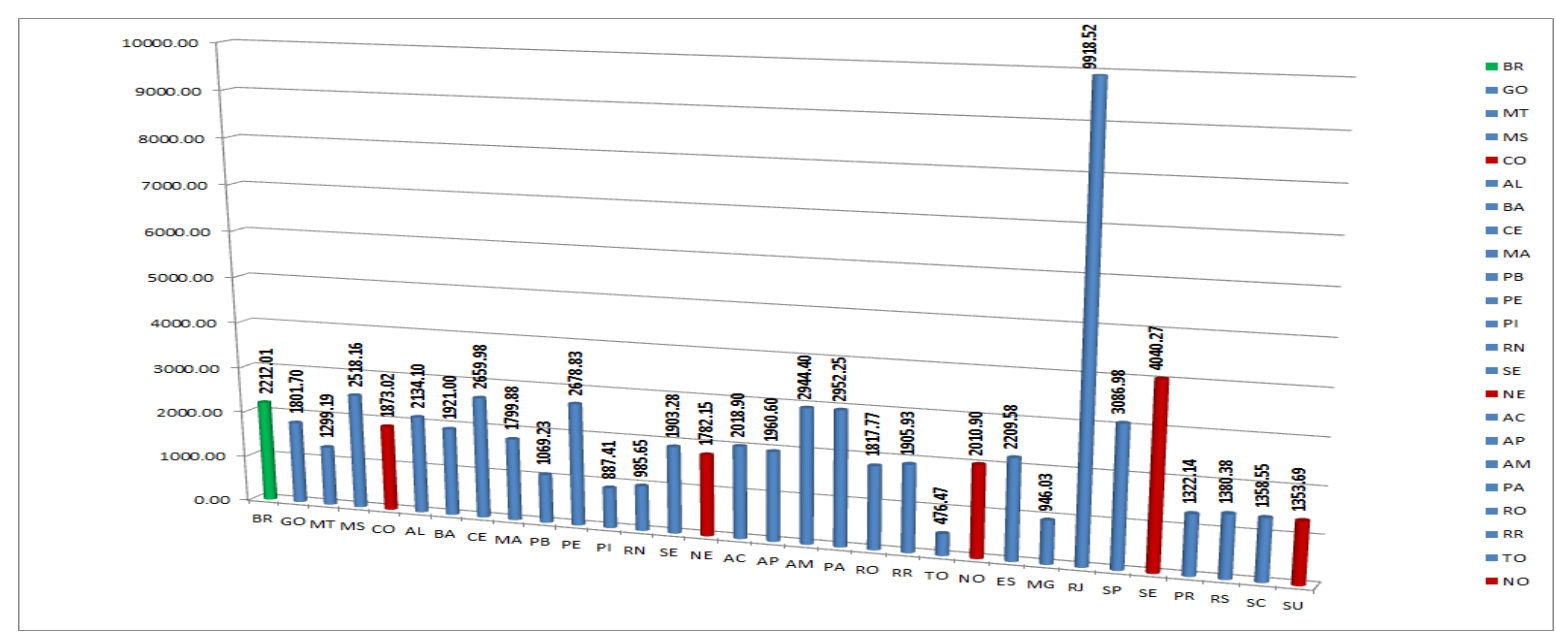

FIGURA 4 - Média mensal de gasto com pessoal e encargos sociais com pessoal (GMPEM) agregado por UF e Grande Região (R \$ 1,00 Func. municipal/mês)

Fonte: Elaborado pelas autoras conforme dados do Finbra (2011) e da Pesquisa de Informações Básicas Municipais do IBGE (2011).

A disparidade do valor do gasto médio mensal por funcionário público, por UF, caracteriza um universo múltiplo encontrado no Brasil quando se trata do quadro de pessoal da administração direta municipal. Esse cenário é reflexo de condutas encontradas na gestão pública municipal, que mesmo sob pressão do ambiente institucional, ainda são conduzidas por ações discricionárias.

\section{Considerações finais}

Ao concluir este artigo, cabe ratificar que o propósito não foi apresentar uma "densidade de equilíbrio" condicionada pela restrição orçamentária e pela demanda de serviços públicos municipais em função do Estado mínimo. Sua finalidade foi mostrar um quadro estimativo da densidade do funcionalismo público municipal por categoria de servidor público agregado por dimensão populacional a partir das Grandes Regiões, sem, nesse momento, discutir qualquer juízo sobre as dispersões das densidades encontradas entre as dimensões populacionais de municípios dentro das Grandes Regiões, o qual merece um esforço maior no aprofundamento de suas causas e efeitos.

Porém, as densidades encontradas apontaram que, nos municípios de pequena dimensão populacional, o número de funcionalismo público da administração direta municipal é maior em relação aos municípios de alta dimensão populacional. Esse fato pode estar correlacionado com o próprio nível populacional e com a Lei de Responsabilidade Fiscal (LRF). No primeiro caso, pressupõe-se que, nos municípios de pequeno porte, a prefeitura acaba sendo a maior empregadora e geradora de renda salarial. $\mathrm{O}$ segundo caso mereceria uma diligência quanto à dimensão do impacto dos gastos com pessoal e encargos nos médios e grandes municípios em relação aos pequenos em relação à LRF. O IFGF do gasto com pessoal mostrou que, dos $8 \%$ dos municípios que se encontravam em "excelentes condições" da gestão nesta função, aproximadamente $90 \%$ são compostos por Entes Federativos com dimensão de até 50 mil habitantes. Contudo, essa questão merece uma análise específica e mais aprofundada. 


\section{REFERÊNCIAS}

ARVATE, Paulo Roberto; BIDERMAN, Ciro. Gasto público eficiente: 91 propostas para o desenvolvimento do Brasil. São Paulo: Topbooks, 2006.

BRASIL. Lei complementar $\mathrm{n}^{\circ}$ 101, de 4 de maio de 2000 (Lei de Responsabilidade Fiscal LRF). Estabelece normas de finanças públicas voltadas para a responsabilidade na gestão fiscal e dá outras providências. Diário Oficial da República Federativa do Brasil, Brasília, DF, 5 maio 2000. Disponível em: <http://www.planalto.gov.br/ccivil_03/leis/lcp/lcp101.htm>. Acesso em: 27 jul. 2013.

BRESSER PEREIRA, Luiz Carlos. O modelo estrutural de gerência pública. Revista de Administração Pública (RAP), Rio de Janeiro: FGV/EBAPE, v. 42, n. 2, p. 391-410, mar./abr. 2008.

CNM - CONFEDERAÇÃO NACIONAL DOS MUNICÍPIOS. Nova administração pública: gestão municipal e tendências contemporâneas. Confederação Nacional dos Municípios (CNM). Brasília: CMN, 2008.

DRAIBE, Sônia Miriam. Avaliação de implementação: esboço de uma metodologia de trabalho em políticas públicas. In: BARREIRA, Maria Cecília Roxo Nobre; CARVALHO, Maria do Carmo Brant de (Org.). Tendências e perspectivas na avaliação de políticas e programas sociais. São Paulo: IEE/PUC-SP, 2001.

FERLIE et al. A nova administração pública em ação. Brasília: UNB/Enap,1999.

FINBRA - SISTEMAS FINANÇAS DO BRASIL. Ministério da Fazenda. Estados e Municípios. Disponível em: <http://www3.tesouro.fazenda.gov.br/estados_municipios/index.asp $\geq$. Acesso em: 25 jul. 2013.

FIRJAN - FEDERAÇÃO DAS INDÚSTRIAS DO RIO DE JANEIRO. Anexo metodológico. <http://www.firjan.org.br/IFGF/ifgf_downloads.html>. Acesso em: 27 jul. 2013.

FIRJAN - FEDERAÇÃO DAS INDÚSTRIAS DO RIO DE JANEIRO. Base de dados: IFGF edição 2012. Rio de Janeiro: FIRJAN, 2012b. Disponível em: <http://www.firjan.org.br/IFGF/ifgf_downloads.html>. Acesso em: 27 jul. 2013.

GUIMARÃES, Tomás de Aquino; SILVA, Eduardo Ramos Ferreira da. Autonomia e flexibilidade na gestão da regulação dos setores de energia elétrica e de telecomunicações no Brasil. In: CONGRESSO INTERNACIONAL DEL CLAD SOBRE LA REFORMA DEL ESTADO Y DE LA ADMINISTRACIÓN PÚBLICA, 5., 2000, Santo Domingo, República Dominicana. Anais... Santo Domingo, 2000.

HOLZNER, Steven. Física para leigos. São Paulo: Alta Books, 2009. 
IBGE - INSTITUTO BRASILEIRO DE GEOGRAFIA E ESTATÍSTICA. Perfil dos municípios brasileiros 2011. Pesquisa de Informações Básicas Municipais. Rio de Janeiro: 2012.

IBGE - INSTITUTO BRASILEIRO DE GEOGRAFIA E ESTATÍSTICA. Pesquisa de Informações Básicas Municipais. Base de Dados: 2011. Disponível em: <http://www.ibge.gov.br/home/estatistica/economia/perfilmunic/2011/default.shtm>. Acesso em: 27 jul. 2013.

JANUZZI, Paulo de Martino. Considerações sobre o uso, mau uso e abuso dos indicadores sociais na formulação e avaliação de políticas públicas municipais. Revista de Administração Pública, Rio de Janeiro, v. 36, n. 1, p. 51-72, jan./fev. 2002.

JANUZZI, Paulo de Martino. Indicadores sociais no Brasil: conceitos, fontes de dados e aplicações. 3. ed. Campinas: Alínea, 2006.

MARTINS, Humberto Falcão. Burocracia e a revolução gerencial: a persistência da dicotomia entre política e administração. Revista do Serviço Público, Brasília, v. 48, n. 1, p. 43-79, 1997.

NEELY, A. et al. Performance measurement system design: a literature review and research agenda. International Journal of Production Economics, n. 4, p. 80-116, 1995.

PASCARELLI FILHO, Mario. A nova administração pública: profissionalização, eficiência e governança. São Paulo: DVS, 2011.

ROCHA, Fabiana. Gasto público eficiente: 91 propostas para o desenvolvimento do Brasil. São Paulo: Topbooks, 2006. p. 97-109.

SANTOS, Clézio Saldanha dos. Introdução à Gestão Pública. São Paulo: Saraiva, 2006.

SILVA, Christian Luiz da; BASSI, Nadia Solange Schimidt. Políticas públicas e desenvolvimento local. In: SILVA, Christian Luiz da (Org.). Políticas públicas e desenvolvimento local: instrumentos e proposições de análise para o Brasil. São Paulo: Vozes, 2012.

SILVA, Cleber Demetrio Oliveira da. Gestão pública. Disponível em: <http://www.rzoconsultoria.com.br/noticias>. Acesso em: fev. 2008. 